\title{
Efficacy of communication amongst staff members at plastic and reconstructive surgery section using smartphone and mobile Whats App
}

ommunication devices have seen a quantum leap over the last several years. Newer and faster means $\triangle$ of communication have literally made the world a much smaller place. Today, most people have accounts with Facebook, Twitter and LinkedIn etc. to name a few. Most of the people use smart phones, which have a whole range of functions apart from the basic ones.

It was therefore, inevitable that it percolated down to almost daily usage in clinical settings. The authors have stated that it is possible to set up a closed user group and communicate efficiently within themselves for optimum patient management with minimal delays. The advantage of a group is clear the message need be sent only once and all the concerned people are in the know. All in all it is a useful system.

However, I would like to point out some precautions, shortcomings and limitations which need to be kept in the back of the mind to ensure that there are no mishaps. No system is foolproof. There are human and technical factors that can cause problems, which may have bad consequences, both medico legally and medically.

The call system too, has undergone several changes. From archaic call books, carried all over the campus, we have now come to instant calls on the mobile phones. Most hospital systems have central messaging in bulk.

Let us look first at some of the advantages of using an application like the authors have used.

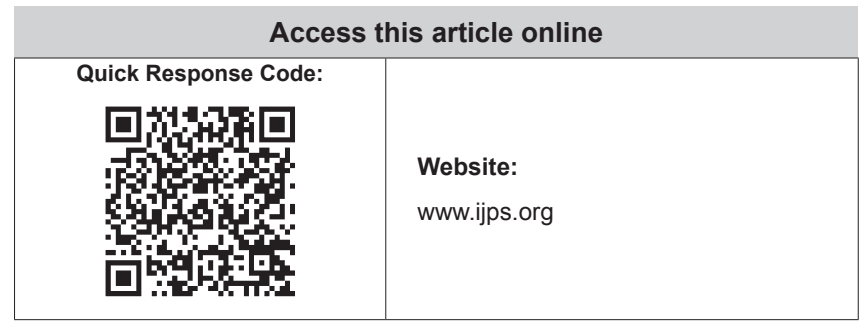

1. User groups can be created, with the information going simultaneously to all people who are involved or will be involved in the care of the patient.

2. X-rays, reports and other clinical photographs can be sent effortlessly, this having a clear advantage over ordinary messaging systems.

3. Many of these applications have facilities to E-mail conversations, thus allowing for a permanent record. Archiving some of these especially with the time recorded may be important for medico legal purposes.

4. As opposed to telephonic conversations where there may be a misinterpretation, for e.g., 15 instead of 50 , written instructions are relatively unambiguous. However human errors can crop up in the form of typos.

However, there can be certain problems, which may crop up from time to time which need to be kept in mind.

1. A net connection, preferably $3 G$ is needed. It does work on edge, but it is much slower and images may not be sent easily. In several countries, 3G services are not uniform. This would mean that the communications may be hampered if a person is outside a coverage area.

2. Delivery reports in a group are not clear. It is extremely important that all the people to whom the message applies must acknowledge the receipt of the message. This is probably the most important step to prevent problems.

3. Needless to say, all the members of the group will need to have smartphones. Many users have still not 'graduated' to smartphones and this may be a limiting factor in the usage. Furthermore there are several operating systems even in smartphones. It has to be ensured that this will work across several systems.

4. One must make sure that negative comments or censures are not transmitted by this method. Apart 
from creating rifts, the medico legal implications are Mukund Jagannathan not clear. As a matter of fact the issue of whether these communications will stand in a court of law is

Department of Plastic Surgery, also unclear. I am sure there will be some issue in the future.

5. Confidentiality has to be maintained, especially with patient data including photographs.

All in all this is a useful method of communication, with the pros and cons to be kept in mind. All with all methods it is not infallible.

How to cite this article: Jagannathan M. Efficacy of communication amongst staff members at plastic and reconstructive surgery section using smartphone and mobile Whats App. Indian J Plast Surg 2013;46:506.

Announcement

\section{Android App}

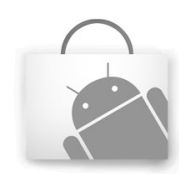

Download

Android application
A free application to browse and search the journal's content is now available for Android based mobiles and devices. The application provides "Table of Contents" of the latest issues, which are stored on the device for future offline browsing. Internet connection is required to access the back issues and search facility. The application is compatible with all the versions of Android. The application can be downloaded from https://market.android.com/details?id=comm.app.medknow. For suggestions and comments do write back to us. 